\title{
Flammability Characteristics OF CHEMical TREATED WOVEN HEMP FABRIC
}

\author{
Mohd Iqbal Misnon ${ }^{1,2}$, Md Mainul Islam ${ }^{1}$, Jayantha Ananda Epaarachchi ${ }^{1}$, Haizhen \\ Chen $^{3}$, Koichi Goda ${ }^{4}$, Md Tawhidul Islam Khan ${ }^{5}$ \\ ${ }^{1}$ Centre for Future Materials and School of Mechanical and Electrical Engineering, Faculty \\ of Health, Engineering and Sciences, University of Southern Queensland, Australia \\ ${ }^{2}$ Faculty of Applied Sciences, Universiti Teknologi MARA, Malaysia \\ ${ }^{3}$ Zhejiang Textile \& Fashion College, China \\ ${ }^{4}$ Department of Mechanical Engineering, Faculty of Engineering, Yamaguchi University, \\ Japan \\ ${ }^{5}$ Department of Advanced Technology Fusion, Faculty of Science and Engineering, Saga \\ University, Japan
}

\begin{abstract}
Woven hemp fabric was treated with sodium hydroxide, commercial flame retardant chemical, and combination of both to increase its fire-retardant properties. Treatments of fire-retardant changed the properties of woven hemp fabric such as increased its fabric shrinkage and density of fibres which ranges from 0.67 to $5 \%$ and 1.43 to $1.53 \mathrm{~g} / \mathrm{cm}^{3}$ respectively. After the treatment, the fire retardancy of the fabric increased tremendously which was observed by the burning, thermogravimetry and limiting oxygen index tests. Some of the samples were not burnt when exposed to flame source and the burning rate needed to be measured under exaggeration of flame at longer time. The limiting oxygen index value increased from 18.6 to 51 after the treatments which explained the scenario happened in the burning tests. Nevertheless, its mechanical properties decreased slightly that ranges from 18 to $32 \%$ and 23 to $39 \%$ for warp and weft respectively compared to untreated fibre.
\end{abstract}

\section{KEYWORDS}

Woven hemp fabric, Fire retardant properties, Fabric properties, Themogravimetry, Limiting oxygen index \& Burning tests

\section{INTRODUCTION}

The fire protection and retardancy of materials have become a serious issue nowadays in many industries. The textile industry is no exception in this matter and there are range of requirements which depend on where the textile material is utilized [1]. In the technical textile application, fabrics that have good flame resistance properties are mostly made of synthetic fibres such as glass, carbon and aramids. These high-performance fabrics are commonly used in special technical requirements and purposes such as materials used in high load bearing application in building infrastructures, marines and aerospace industries [2].

Hemp is a well-known fibre in the textile industry. It belongs to a group with jute and flax as the primary material in the production of heavy and medium-weight fabrics in the linen industry. Hemp is currently used to produce hats, shirts, shoes, backpacks and jeans. It is also used for producing paper fibres as well as bedding for animals [3]. Hemp composed of $68-74.4 \%$ of cellulose, $15-22.4 \%$ of lignocellulosic, lower in lignin, pectin and waxes, which makes this fibre relatively strong $[4,5]$. It is worth mentioning that even it possesses good properties, there are DOI:10.5121/msej.2018.5101 
fewer works on enhancing its fire retardant properties. Thus, efforts on improving these properties are necessary since its application is not only limited to apparel and textiles but also in various engineering fields such as in panel and other composite material productions [5-8]. Observing at the amount of cellulose content in hemp, one can predict hemp tolerances against flame. There are no other ways to enhance its fire retardant properties except by employing fire retardant finishes or treatments.

It is well-known that there are three (3) components of combustion; heat, fuel, and oxygen [9]. These three components form some complex processes in textile combustion. When a textile fibre is exposed to heat, it pyrolyses at 'pyrolysis temperature', while volatile liquids and gases act as fuels for further combustion. The temperature should be equal to or greater than 'combustion temperature' after pyrolysis to burn flammable volatile liquids in the presence of oxygen thus producing products such as carbon dioxide and water. Textile fibre is continuously ignited as long as there is heat from an external source which raises its temperature until it degrades. Therefore, fire retardant functions to interfere at least one of the three components mentioned above [2].

Some chemical compounds, for instance, bromides, tri-hydroxide and phosphates are very useful to enhance the fire retardant of cellulosic fibres [9]. Their role includes, directing thermal degradation to fuel-poor pyrolytic paths, coating of the substrate to exclude oxygen, preventing evolution of combustible gases, diluting fuel formed by pyrolysis, and to dissipate heat away from the flame front [10]. The rate of the initial rise in temperature depends on the specific heat of the fibre, thermal conductivity, and the latent heat of fusion. Since the 1950s up to present, many researchers have been conducted on fire retardant chemicals in many aspects such as its toxicity, durability and new chemical products $[2,11,12]$.

Nevertheless, the most determinant in the selection of fire retardant finishes of the textile material is cost. Manufacturers are very concerned on how the finishes are applied on the material especially on natural fibres. Applying complicated finishing on the natural fibre will increase the cost. Other alternatives are using pre-treated cellulosic fire retardant fibres which are available at reasonably low cost. Other than that, applying commercial fire retardant chemicals which are available in the market is a good option.

A simple finishing material that is meant to increase fire retardancy of natural textile fibres is sodium hydroxide $(\mathrm{NaOH})$. Shafizadeh, et al. [13] in their work, evaluated the mechanistic of fire retardant and ranked $\mathrm{NaOH}$ in their list of retardants. Chen, et al. [14], on the other hand, worked on the effects of fire retardant addition on the combustion properties of a charring fuel and used $\mathrm{NaOH}$ as the fire retardants. Mostashari, et al. [15] investigated the effect of $\mathrm{NaOH}$ deposition on the cotton the rmogravimetry. These works show that $\mathrm{NaOH}$ is recognised as a fire retardant for natural textile fabric thus it is worth trying it on the hemp fabric. The purpose of this work is to assess fire retardant properties of wo

ven hemp fabric (WHF) treated with the commercial fire retardant as well as sodium hydroxide chemicals. It is also to determine the fire retardant performances in between the commercial fire retardant, sodium hydroxide treatments, and combination of both for hemp fabric. In this work, three types of treatment were applied on woven hemp fabric including sodium hydroxide $(\mathrm{NaOH})$, flame retardant (FR) solution and combination of $\mathrm{NaOH}$ and FR chemicals. The fabrics were treated by employing dips and nips method. The fire retardant properties were evaluated by means of burning test, thermogravimetric analysis as well as limiting oxygen index. Measurement on the fabric physical properties were also done to understand the changes before and after the treatments, and tensile test were performed to analyse the WHF mechanical properties affected by the treatments. 


\section{Materials AND Method}

\subsection{Materials}

A commercial 'heavy fabric' grade WHF was supplied by Hemp Wholesale Australia. Table 1 shows the physical properties of the WHF. According to the specifications given by the supplier, the fabrics were produced from $100 \%$ yarn hemp in both warp and weft. The yarns were converted from cleaned hemp fibre through spinning processes and the twist given was 430 twists per meter. These yarns were then converted into fabric via weaving processes and the fabrics were woven by employing loose plain weave (taffeta) structure. Commercial grade $\mathrm{NaOH}$ was supplied by Science Essential Australia while commercial flame retardant (FR) chemical was supplied by Cyndan Chemicals, Australia. According to the supplier, the main active ingredient in this flame retardant is ammonium polyphosphate. Information from the technical and material datasheet says this chemical is water-based, not classified as hazardous, and is environmental friendly.

Table 1. Physical properties of woven hemp fabric

\begin{tabular}{|c|c|c|c|}
\hline \multicolumn{3}{|l|}{ Properties } & $\begin{array}{l}\text { Standard } \\
\text { Methods/References }\end{array}$ \\
\hline \multicolumn{4}{|l|}{ Physical Properties } \\
\hline \multicolumn{2}{|l|}{ Weave Structure } & Plain/Taffeta & \\
\hline \multirow{2}{*}{ Fabric Density (per $2 \mathrm{~cm})$} & Warp & 25 & ASTM: D3775 \\
\hline & Weft & 23 & ASTM: D3775 \\
\hline \multirow{2}{*}{$\begin{array}{l}\text { Total yam weight (measured) } \\
\left(\mathrm{g} / \mathrm{m}^{2}\right)\end{array}$} & Warp & 119.813 & {$[16,17]$} \\
\hline & Weft & 116.859 & {$[16,17]$} \\
\hline \multicolumn{2}{|l|}{ Thickness (mm) } & 0.417 & ASTM: D1777 \\
\hline \multirow[t]{2}{*}{ Yam Size (Tex) } & Warp & 90.459 & ASTM: D1907 \\
\hline & Weft & 92.970 & ASTM: D1907 \\
\hline \multirow{2}{*}{ Yam Crimp (\%) } & Warp & 6.0 & ASTM: D3883 \\
\hline & Weft & 9.3 & ASTM: D3883 \\
\hline \multicolumn{2}{|l|}{ Density of Fibre $\left(\mathrm{g} / \mathrm{cm}^{3}\right)$} & 1.473 & [16] \\
\hline
\end{tabular}

\subsection{Chemical Treatment and Density Measurement}

WHF was treated with $\mathrm{NaOH}$, FR and combination of both chemicals ( $\mathrm{NaOH}+\mathrm{FR})$. For the first treatment, fabrics were soaked in $\mathrm{NaOH}$ solution (10\% concentrations) for 3 hours at room temperature. The fabrics were next washed with distilled water for several times to remove excess alkali from the fabric. The washed fabrics were dried at room temperature for 8 hours, and then oven dried at $100^{\circ} \mathrm{C}$ for another 6 hours. The subsequent neutralisation treatment was abandoned to retain the alkali cellulose formed on the fabric surface [15]. The dried fabrics were stored in a sealed plastic bag to avoid atmospheric moisture contamination prior to chemical and thermal analyses.

For the FR treatment, according to the supplier, the FR can be used as it is by spraying or dipping, and drying is not necessary. However, in this work, 'dip and nip' method was employed to treat the fabrics. The nipping process was set carefully so that the chemical uptake is consistent and maintained within the range of $100-105 \%$. The treated fabrics were then left to dry at room temperature for 8 hours.

Whilst for the combination of $\mathrm{NaOH}+\mathrm{FR}$, the fabric was firstly treated with $\mathrm{NaOH}$ and followed by the FR using the procedures mentioned above. The abbreviation for WHF; untreated, treated with sodium hydroxide, treated with FR chemical and treated with sodium hydroxide combined with FR are WHF-UT, WHF-NaOH, WHF-FR and WHF-NaOH+FR respectively.

The density of the treated fabrics were measured to determine the changes before and after treatment using Multipycnometer MVP D160E. Helium gas was used as the displacement 
medium. The helium was added to the fibres under vacuum condition to ensure that all interior air cavities in the submerged fibres (e.g. the fibre lumen) were filled with helium. The data reported are the average and standard deviation of 3 measurements [16].

The chemical uptake or pick-up for all treated WHF was calculated using Eq. (1) $[18,19]$.

$$
\text { Chemical pickup (\%), } A=\frac{W_{2}-W_{1}}{W_{1}} \times 100
$$

Where, $W_{2}$ is the weight of fabric after treatment and $W_{1}$ is the weight of fabric before treatment and both should be in dry condition.

The fabric shrinkages after the treatments were measured using Eq. (2) as follows;

$$
\text { Fabric Shrinkage (\%), } B=\frac{L_{2}-L_{1}}{L_{1}} \times 100
$$

Where, $L_{2}$ is the length of fabric after treatment and $L_{1}$ is the length of fabric before treatment.

The weight of each fabric (untreated and treated) was calculated by calculating total weight of warp and weft yarn. The weight can be measured using the Eq. (3) [16, 17] as follows;

$$
\text { Fabric weight }\left(g / m^{2}\right), W=\frac{N_{1}\left(1+C_{1}\right)}{P_{1}}+\frac{N_{2}\left(1+C_{2}\right)}{P_{2}}
$$

Where $N$ is the yarn size, $C$ is the yarn crimp percentage while subscripts 1 and 2 refer to warp and weft yarn respectively. $\mathrm{P}$ is the yarn spacing in $\mathrm{mm}$. The measurement and calculation procedures for yarn spacing $(P)$ of the WHF are shown in Misnon, et al. [16].

\subsection{Flammability Test}

Ignition time and burning behaviour as well as flame spread properties were investigated to determine the flammability properties of treated hemp fabrics. Ignition time and burning behaviour of the samples were measured using James Heal and Halifax Flammability Tester in accordance with $\mathrm{BS} 5438$ at $24^{\circ} \mathrm{C}$ and $65 \%$ relative humidity room condition. In this test, a sample with the dimension of $220 \times 170 \mathrm{~mm}$ was mounted in a steel frame as shown in Figure 1(a) after being conditioned for 24 hours also at $24^{\circ} \mathrm{C}$ and $65 \%$ relative humidity. A standardized flame source was applied to the surface from the bottom, and the ignition time was set at 12 seconds. Three (3) specimens from warp and weft samples for each textile fabric were processed and average was taken for interpretation. The ignition time, flame and smouldering time (after glows) and burning characteristics were recorded [19].

The spreading of flame test was conducted in accordance with ISO 6941 by mounting the fabric sample on a steel frame as shown in Figure 1 (b) held vertically on the James and Halifax Flammability Tester instrument. The specimen was exposed from below to flame source for 12 seconds. At four (4) different spots, a standardized marker thread was placed to determine spreading rate of flame. Two (2) threads were placed horizontally at two different heights across the sample surface that were at $300 \mathrm{~mm}$ and $600 \mathrm{~mm}$ horizontally to measure vertical spreading flame. The other two (2) threads were placed vertically on both left and right sides of the fabric specimens to measure the flame spreading rate horizontally [20-23]. When the flame spread and reached any of mark, the thread was burnt and the respective marker timer was stopped. Three (3) specimens $(600 \times 170 \mathrm{~mm})$ of warp and weft for each treated fabric type were conditioned and the time of flame spreading for both vertical and horizontal were recorded and their average was measured. 


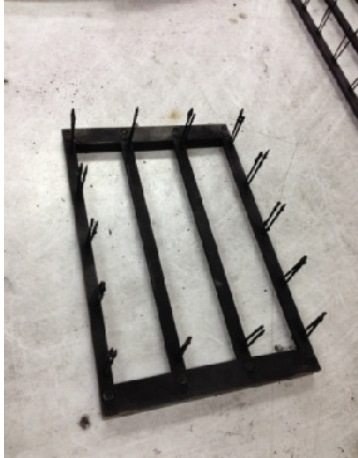

(a) BS 5438

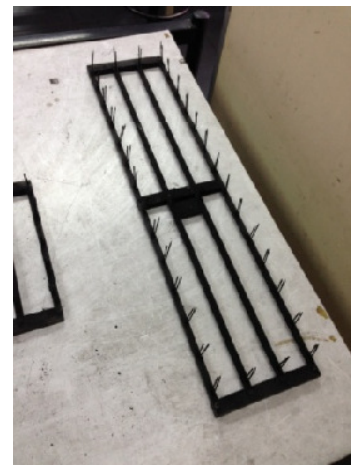

(b) ISO 6941

Figure 1. Steel frame used to mount fabric sample following (a) BS 5438 and (b) ISO 6941

\subsection{Thermogravimetric Analysis}

Thermogravimetric analyses (TGA) were carried out on a TA Instruments Model TGA Q500, operating under nitrogen and air atmosphere using a platinum pan. The runs were performed over a temperature range between 30 and $600^{\circ} \mathrm{C}$ at $10^{\circ} \mathrm{C} / \mathrm{min}$ heating rate and $20 \mathrm{ml} / \mathrm{min}$ flow.

\subsection{Limiting Oxygen Index}

Limiting oxygen index (LOI) is a method to determine the minimum oxygen concentration in an oxygen/nitrogen mixture that will sustain the flame. It is a convenient, reproducible, and inexpensive way of determining the tendency of a material to sustain flame. The LOI test was carried out using an LOI instrument model number of M606 in accordance with ASTM: D2863. A test sample of $150 \times 50 \mathrm{~mm}$ was placed in a transparent test chamber and ignited at the top. The oxygen concentration in the mixture of oxygen and nitrogen was increased slowly until the sample sustained burning. The volume fraction of the oxygen in the gas mixture was reported as the LOI.

\subsection{Tensile Test}

The tensile properties (ASTM: D5034) of hemp fabrics were characterized using universal testing machine, MTS Alliance RT/10. A $75 \mathrm{~mm}$ wide test specimen was cut in the desired direction (warp or weft) and then equal numbers of yarns were removed from both sides until the specimen width was reduced to $50 \mathrm{~mm}$. The same procedure was followed for test strips in both warp and weft directions. The tensile tests were performed using a gauge length of $75 \mathrm{~mm}$ and a crosshead speed of $10 \mathrm{~mm} / \mathrm{min}$. The cross-sectional area used to convert load into stress was calculated from the test specimen width and the thickness of fabric obtained from the fabric characterization $[24,25]$.

Typically, the tensile curve (in stress-strain curve) for most of the textile fabrics initially started in nonlinear and then its slope increased slowly until finally becoming linear. The mechanical properties of textile fabrics could not be determined under the nonlinear curve. Therefore, a linear trend line was drawn to extend the linear part of the curve to the axis of strain in order to determine the tensile stress, tensile modulus as well as strain at peak of hemp fabric [16, 26].

\section{RESULTS AND DISCUSSION}

\subsection{Treatment Effects on the Physical Properties of Woven Hemp Fabric}

Changes of the physical properties of WHFs before and after chemical treatment are shown in Table 2. The chemical pick-up on WHF was measured based on the changes in weight before and after treatment with the assumption that there is no yarn lost when the treatment is done. The 
weight of WHF fabric which was treated with $\mathrm{NaOH}$ (WHF-NaOH) and FR (WHF-FR), increased by 18.19 and $24.94 \%$ respectively whilst the weight of WHF treated with both chemicals (WHF-NaOH+FR) was recorded even higher which was $30.10 \%$ higher due to the deposition of treatments. The density of treated WHF increased drastically as compared to the untreated WHF due to effect of the treatment applied on them.

The changes in fabric dimensions were also observed where all the treated samples experienced shrinkage for both warp and weft directions. The shrinkage from the sample treated with $\mathrm{NaOH}$ (WHF-NaOH) showed the highest among all the samples. The combination of $\mathrm{NaOH}$ and FR treatment shrunk the sample (WHF-NaOH+FR) a bit lower than the $\mathrm{NaOH}$ treatment and the least change was shown by the sample treated with only FR (WHF-FR). Observing the differences in shrinkage percentages of all the samples, it seems that the $\mathrm{NaOH}$ treatment is responsible for the higher shrinkage. It can be observed that with the $\mathrm{NaOH}$ alone, the shrinkage was recorded the highest whilst FR shows the lowest among all the samples. In the combined treatment, WHF was firstly treated with $\mathrm{NaOH}$ and this process made the fabric shrunk but the shrinkage was a bit lower than WHF-NaOH most probably due to the FR treatment.

Table 1. Chemical pick-up, fibre density and fabric shrinkage properties of all the WHF samples

\begin{tabular}{|l|c|c|c|c|}
\hline Sample & $\begin{array}{l}\text { Chemical } \\
\text { Pick-up (\%) }\end{array}$ & \multirow{2}{*}{$\begin{array}{l}\text { Density } \\
\mathbf{( g / c m}^{\mathbf{g}} \mathbf{)}\end{array}$} & \multicolumn{2}{|l|}{ Fabric Shrinkage (\%) } \\
\cline { 4 - 6 } & N/A & & Warp & Weft \\
\hline WHF-UT & 18.19 & 1.51 & N/A & N/A \\
\hline WHF-NaOH & 24.94 & 1.54 & 5 & 3 \\
\hline WHF-FR & 30.10 & 1.53 & 4.67 & 0.67 \\
\hline WHF-NaOH+FR & & & & \\
\hline
\end{tabular}

During the alkali treatment, $\mathrm{NaOH}$ has removed the organic component in the WHF. In the textile industry, this treatment is similar to 'mercerisation' where concentrated alkaline is applied to the cotton fabric. This process is meant to increase lustre, hygroscopicity, strength as well as the dye affinity of the cotton fabric $[15,27]$. In general, cotton is similar to hemp, which is categorised under natural textile fibres; thus, similar effect is expected to happen to WHF. Under the action of this treatment, physicochemical and structural modification of cellulose takes place. Apart from the hemicellulose and lignin removal and in structural modification by alkali treatment, the structure of the fibre inter-converts from alpha-cellulose and beta-cellulose mixture to a thermodynamically favourable cellulose II polymorph [27]. This chemical reaction lead to formation of alkali cellulose, physical reaction, to intensive swelling of fibres and structural reactions, and to a change in the arrangement of units in the cellulose macromolecule. When the fibre swells, its volume undergoes considerable changes; increases in water absorption due to the increase of pore size and then leads to the increase in cross-section of fibre by 40 to $50 \%[15,27]$.

The Scanning electron microscopic (SEM) images in Figure 2 (a) show the untreated WHF-UT sample. From the cross-section of the image, the fibres have thin and lenticular shape and its surface is rough due to hemicellulose and lignin. In contrast, WHF-NaOH sample exhibits the changes in fibre's cross-section from elliptical to become rounder suggesting that the fibres were swollen and the diameter was increased which can be seen from Figure 2 (b). The surface of the fibres became clean due to the removal of hemicellulose, lignin and fat [15, 27].

From the reduction in hemicellulose and lignin, the percentage of cellulose is presumably increased. This explains why the fibre density of WHF-NaOH was found a bit higher $\left(1.51 \mathrm{~g} / \mathrm{cm}^{3}\right)$ in comparison with the untreated fabrics $\left(1.47 \mathrm{~g} / \mathrm{cm}^{3}\right)$. The density of hemp fibre can vary depending on how much the cellulose content is in the fibres because the higher the cellulose content the denser the fibre would be [28]. As a consequence from the swollen fibres, the fabric (WHF-NaOH) experienced shrinkage because the yarn released tension which was developed during the processes such as yarn spinning, fabric weaving and fabric finishing [29]. 
In terms of FR treatment, there were FR particles (marked in red circles) with the size ranging from several micro- to nanometres deposited on the fibre surface (Figure 2 (c)). Apart from the fibre cross-section changing from lenticular to become rounder, the surface was observed quite clean from the hemicellulose and lignin as compared to Figure 2 (a). The increment of weight of the treated WHF leads to the increase of its density and the reason for this is similar to WHF$\mathrm{NaOH}$. From Table 2, the increment on weight for WHF-FR due to chemical deposition was recorded $24.94 \%$, which was a bit higher than the WHF-NaOH sample (18.19\%).

The WHF-NaOH+FR samples exhibited the highest chemical pick-up because of the combined treatment with $\mathrm{NaOH}$ and FR chemicals. The sputtered surfaces in Figure 2 (d) were probably due to the reaction between both chemicals. Since the main reactive chemical in FR is ammonium polyphosphate, the presence of phosphorus (or sulphur) derivatives were able to generate acid or acid-forming agents [30]. Most of the fire retardant chemicals (for natural biomass/fibre) are a bit acidic and this is for creating a good durability on the natural fibres and gives some balance for the treated fibres when subjected to other treatments. However, the acid is not strong enough to rough the fibres as what happened to the cotton fibre treated with fire retardant as found by Lam, et al. [29]. As for the $\mathrm{NaOH}$ treatment, since no neutralisation is happened, the content of the alkali remaining in the fibre can be said higher suggesting that some reactions between the chemicals occurred (refer section 2.2). Therefore, the sputter, as shown in WHF-NaOH+FR surface, is most likely salts, products of the reaction between a generated acid and pure alkali from FR and $\mathrm{NaOH}$, respectively. The shrinkage of this sample was a little lower than the sample WHF-NaOH but higher than WHF-FR. This is because the fabric has been firstly treated with alkali and dried before it was treated with FR chemical. In addition, the consequences of the treatment are the elimination of hemicellulose and lignin on top of addition of salt on the fibre surface which latter causes the increment of the density of this sample.

The changes in physical properties due to the treatment definitely change the quality of hemp fabric. In the application, as the hemp shrinks after the chemical treatments, the users need to add some allowance before the treatments to make sure the hemp fabric is adequate for their usage. Since the treated hemp fabrics do not go through any neutralisation process, they cannot be used as apparel and garment products but can be used in furnishing, backing layer as well as in technical application such as composite reinforcements and insulations. The cost borne by the manufactures for using these treated fabrics will be increased due to the additional fabric and treatments.

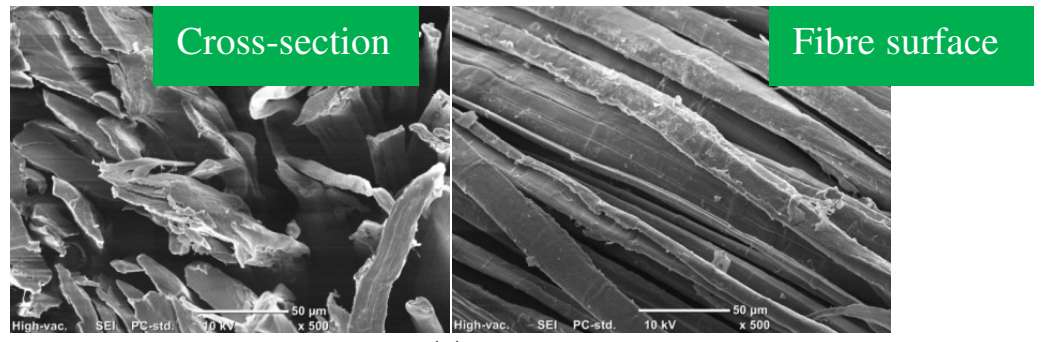

(a)

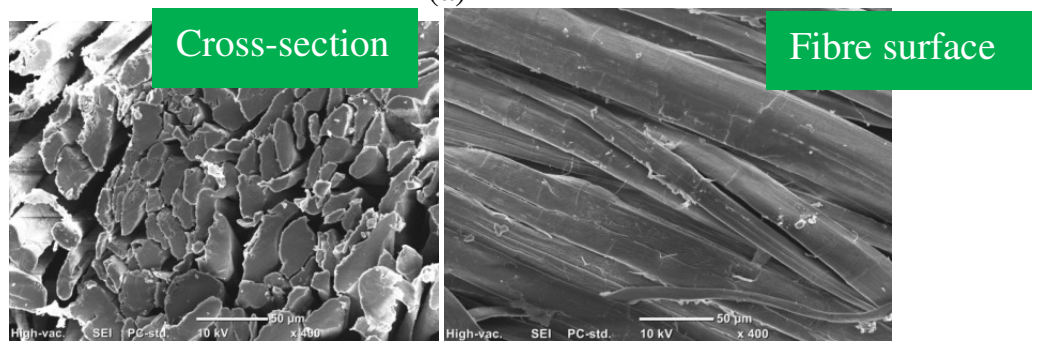

(b) 

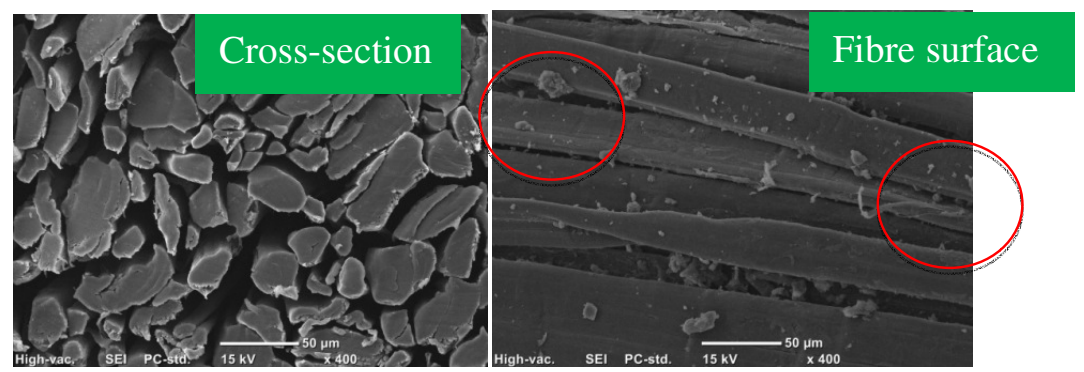

(c)

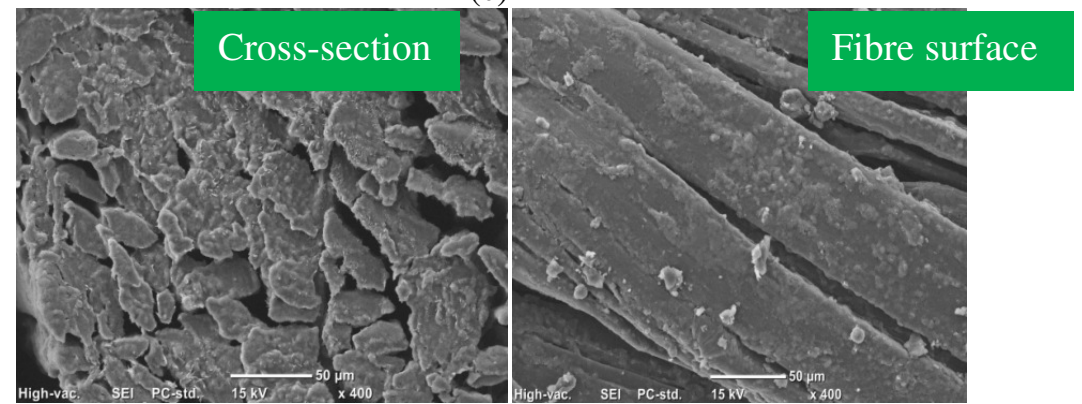

(d)

Figure 1. Scanning electron microscopic images of all WHF samples fibres in cross-section and fibre surface views; (a) untreated, (b) $\mathrm{NaOH}$, (c) FR, and (d) $\mathrm{NaOH}+\mathrm{FR}$

\subsection{Effect of Fire Retardant Treatment on Ignition Time and Burning Behaviour}

The differences in the burning behaviour of the untreated and fire retardant treated WHF can be observed from the ignition time and burning behaviour tests. In this test, the time exposure to small flame was set for $12 \mathrm{~s}$. The fabric was exposed to flame in both warp and weft directions and the results for each sample is the average of 3 specimens. Table 3 shows the results of ignition time for all fabric samples in this work.

Among the samples, only the untreated sample was burnt completely. There are no notable differences between the times taken in between warp and weft specimens. The ignition time for WHF was about 3 to $3.5 \mathrm{~s}$ and after the flame source was removed, the fabric burnt rapidly. The time taken for the whole specimen to burn was between 247 to $249 \mathrm{~s}$. When the flame was extinguished, the fabric continued to smoulder for another $27 \mathrm{~s}$ and left a very poor residue behind. Figure 3 (a) shows the image of the burning test, which was taken when the fabric was still burning while Figure 3 (b) is after the flame extinguished. It was also observed that the fabric was burnt with yellow flames, released smoke in white colour and smell like burnt paper, which is common for natural fibres.

In the case of WHF-NaOH sample, the time taken for the fabric to ignite was longer than the WHF-UT sample which was about 7 to $8 \mathrm{~s}$. Moreover, typically, the flame only continued for about 3 to $5 \mathrm{~s}$ after the fabric was exposed to flame for $12 \mathrm{~s}$. Figure 3 (c) shows the burning test for the WHF-NaOH right after the flame was self-extinguished and it was observed that the fabric continued to smoulder for another 42 to $46 \mathrm{~s}$ before the fire was totally out. The part that was exposed to flame source was burnt to ash (including burning during smouldering) and can be seen in Figure $3(\mathrm{~d})$. The total burning process for sample WHF-NaOH from the flame exposure until it was extinguished were $57 \mathrm{~s}$ and $63 \mathrm{~s}$ for both warp and weft directions respectively. Other characteristics observed during the burning were, the flame was yellow in colour, released white coloured smoke and produced an intense smell most probably due to the burning of alkali content 
in the fabric. The fire retardant property of the WHF was improved with $\mathrm{NaOH}$ treatment in comparison with the untreated sample (WHF-UT), in terms of the total burning times.

Table 2. Results of burning behaviour and ignition time

\begin{tabular}{|l|l|l|l|l|l|l|}
\hline Sample & \multicolumn{2}{|l|}{ Ignition time (s) } & \multicolumn{2}{l|}{ Total burning time (s) } & \multicolumn{2}{l|}{ Duration of afterglow (s) } \\
\hline $\begin{array}{l}\text { BS } \\
5438: 1976\end{array}$ & Warp & Weft & Warp & Weft & Warp & Weft \\
\hline WHF-UT & $3.5(0.3)$ & $3.4(0.1)$ & $247.3(2.61)$ & $\begin{array}{l}249(5.29 \\
)\end{array}$ & $274(7.94)$ & $276(6.24)$ \\
\hline $\begin{array}{l}\text { WHF- } \\
\text { NaOH }\end{array}$ & $8(0.9)$ & $7(0.91)$ & $15(1.53)$ & $17(2.01)$ & $57.7(7.51)$ & $63(13.96)$ \\
\hline WHF- FR & $\mathrm{X}$ & $\mathrm{X}$ & $\mathrm{X}$ & $\mathrm{X}$ & $\mathrm{X}$ & $\mathrm{X}$ \\
\hline $\begin{array}{l}\text { WHF- } \\
\text { FR+NaOH }\end{array}$ & $\mathrm{X}$ & $\mathrm{X}$ & $\mathrm{X}$ & $\mathrm{X}$ & $\mathrm{X}$ & $\mathrm{X}$ \\
\hline
\end{tabular}

$\mathrm{X}$ - Indicates the expected event had not happened.

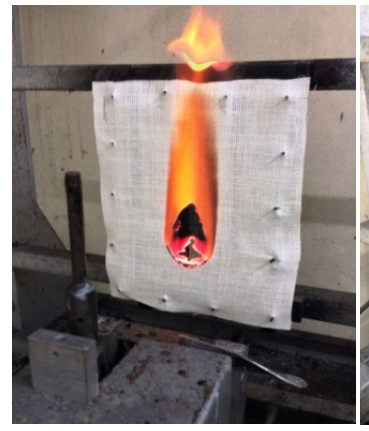

(a)

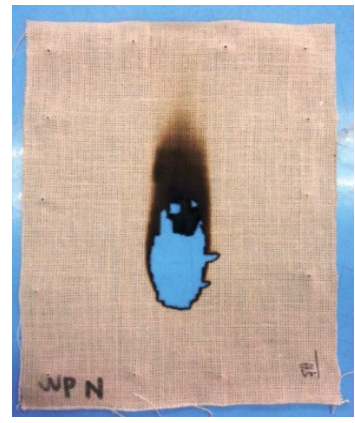

(d)

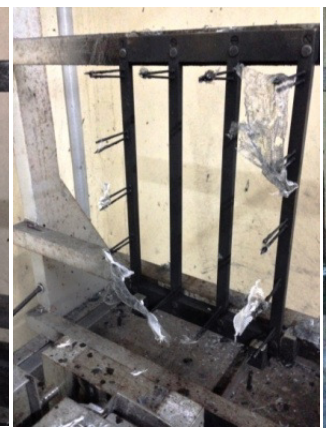

(b)

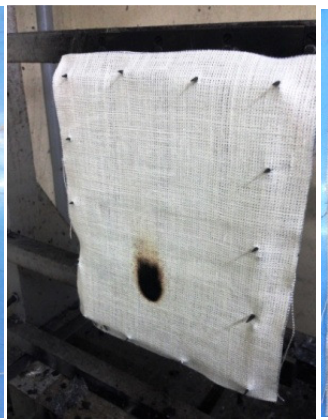

(e)

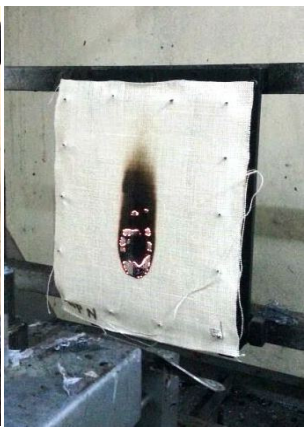

(c)

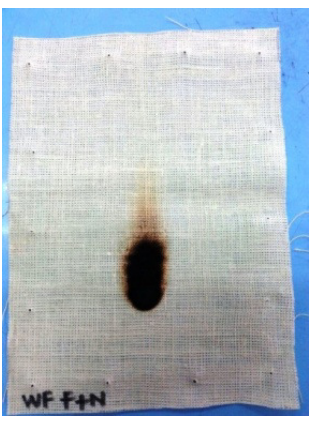

(f)

Figure 2. Burning characteristic of WHF sample; (a) WHF-UT sample during the test, (b) WHF-UT sample after burning and, (c) WHF-NaOH sample smouldering (after glow). (d) WHF-NaOH, (e) WHF-FR and, (f) WHF-NaOH+FR after burning characteristic test

Based on Table 3, sample WHF-FR shows good properties against the fire. It was observed that neither ignition nor flame sparked on the fabric sample when exposed to the flame. Only the charring processes happened to the WHF on the contact point to the flame source, and the carbonaceous char was spread a bit to the upper part direction of the fabric during exposure to the flame source. Table 3 (e) shows the WHF-FR sample after flame source exposure and its char formation size was small compared to the WHF-NaOH sample. It was also observed that the exposure of WHF-FR to the flame produced white smoke and intense smell similar to the WHF$\mathrm{NaOH}$ sample. In Figure 3 (f), the WHF sample treated with $\mathrm{NaOH}$ and FR chemicals (WHF$\mathrm{NaOH}+\mathrm{FR}$ ) exhibited effects comparable with WHF-FR. Neither ignition nor smoulder was 
observed during the flame test and it also produced white smoke and intense smell when exposed to flame source.

In the case of WHF-FR and WHF-NaOH+FR, char was formed which successfully extinguished the fire. This char is undoubtedly attributed to ammonium polyphosphate and $\mathrm{NaOH}$ contents in the FR chemical [30]. Char formation can make the carbon and hydrogen stay in the condensed phase thus reducing the mass of volatile combustible degradation fragment evolved. Char also acts as thermal insulator by remaining on the virgin polymer substrate, absorbing some of the heat input thereby reducing the heat flux reaching the virgin polymer [31, 32]. As the char surface temperature increases, re-radiation lost increases significantly therefore assisting to prevent thermal degradation. Char formed at substrate surfaces also acts as a physical barrier to obstruct the flow of combustible gases generated from the degradation of the underlying unburnt material and hindering the access of oxygen to the surface of the polymer [32]. In the case of WHF-NaOH, it can be said that the extinguishing of fire was not only due to the char formation because there was smouldering after the fire was put out (Figure 3 (c)). This might be due to some combustible gas leakages that reacted with oxygen and continued to burn the residual virgin polymer of hemp fabric (charred parts).

\subsection{Spreading of Flame}

The spreading of flame was tested for the untreated and all treated WHF samples. The time taken for flame travel along the fabric was recorded at 3 different marks (yarn tread) which were, at the height of $300 \mathrm{~mm}, 600 \mathrm{~mm}$ and to the horizontal direction either left or right. The burning rates were calculated by means of dividing the length of fabrics vertically $(600 \mathrm{~mm})$ by their burning times in seconds [15]. The flame spreading results for all WHF samples are shown in Table 4 and it was found that only the untreated sample (WHF-UT) was burnt to the whole specimen. It took only 22 and $23 \mathrm{~s}$ for the flame to reach first mark after exposed to the flame source and the total times to reach the second mark were recorded 46 and $50 \mathrm{~s}$ for both warp and weft respectively. The movement of flame to the horizontal part was slower which recorded as 77 and $74 \mathrm{~s}$ in total of time for both warp and weft specimen respectively. The burning of this WHF-UT sample can be depicted in Figure 3 (a), when it was exposed to flame source, and Figure 3 (b) when it reached all three marks. The burning rate of this sample was measured in the range of 1.2 to 1.3 $\mathrm{cm} \mathrm{s}^{-1}$ for both warp and weft directions.

In contrast to the untreated WHF-UT sample, any of the treated woven hemp samples did not reach all three marks because these samples did not burn when they were exposed to the flame source. Therefore, the burning time cannot be measured for all the treated WHF. With such a result as what has been discussed in ignition time and burning behaviour test previously, this flame spreading test results was expected. The short flame source exposure in $12 \mathrm{~s}$ did not affect any treated WHF sample.

Table 3. Flame spreading results of all woven hemp fabrics

\begin{tabular}{|c|c|c|c|c|c|c|c|}
\hline & \multicolumn{2}{|c|}{$\begin{array}{l}1^{\text {st }} \text { mark } \\
(300 \mathrm{~mm})\end{array}$} & \multicolumn{2}{|c|}{$\begin{array}{l}2^{\text {nd }} \text { mark } \\
(600 \mathrm{~mm})\end{array}$} & \multicolumn{2}{|c|}{ Horizontal } & $\begin{array}{l}\text { Burning Rate } \\
\left(\mathrm{cm} \mathrm{s}^{-1}\right)\end{array}$ \\
\hline ISO 6491 & warp & weft & warp & weft & warp & weft & Vertical \\
\hline WHF-UT & $\begin{array}{l}22.33 \\
(1.53)\end{array}$ & $\begin{array}{l}22.25 \\
(1.09)\end{array}$ & $\begin{array}{l}46.17 \\
(1.04)\end{array}$ & $\begin{array}{l}50.43 \\
(1.50)\end{array}$ & $\begin{array}{l}77.08 \\
(1.01)\end{array}$ & $\begin{array}{l}73.17 \\
(1.04)\end{array}$ & $1.2-1.3$ \\
\hline $\mathrm{NaOH}$ & $\mathrm{X}$ & $\mathrm{X}$ & $\mathrm{X}$ & $\mathrm{X}$ & $\mathrm{X}$ & $\mathrm{X}$ & $\mathrm{X}$ \\
\hline FR & $\mathrm{X}$ & $\mathrm{X}$ & $\mathrm{X}$ & $\mathrm{X}$ & $\mathrm{X}$ & $\mathrm{X}$ & $\mathrm{X}$ \\
\hline $\mathrm{NaOH}+\mathrm{FR}$ & $\mathrm{X}$ & $\mathrm{X}$ & $\mathrm{X}$ & $\mathrm{X}$ & $\mathrm{X}$ & $\mathrm{X}$ & $\mathrm{X}$ \\
\hline
\end{tabular}

$\mathrm{X}$ - Indicates the expected event had not happened. 
Therefore, in order to investigate further about the WHF flammability properties especially the burning rate or char burning rate, the flame exposure was decided to be extended from $12 \mathrm{~s}$ to 2 minutes $(120 \mathrm{~s})$. In this way, particularly for the FR treated fabrics, the burning rate or char formation rate can be measured under exaggeration of flame. This is also to imitate a real fire situation in which the hemp fabric may be exposed to continuous fire from other sources such as burning woods, papers etc. Table 5 shows the results of the spreading flame test of all treated WHF samples subjected to 2-minute flame exposure. Even with the longer exposure to flame, any of all types of treated samples did not reach the first mark. The WHF-NaOH sample did burn but as soon as the flame source was removed, the flame continued for several seconds before extinguishing with some smouldering for another 20 to $50 \mathrm{~s}$. However, the flame and smoulder burned the char into ash and this was similar to what has been discussed in Section 3.2.

Table 4. Flame spreading results for all treated samples when subjected to 2-minute flame exposure

\begin{tabular}{|l|l|l|l|l|l|l|}
\hline & \multicolumn{2}{|l|}{$\begin{array}{l}\text { st mark } \\
(300 \mathbf{~ m m})\end{array}$} & $\begin{array}{l}\mathbf{2}^{\text {nd }} \text { mark } \\
(\mathbf{6 0 0} \mathbf{~ m m})\end{array}$ & \multicolumn{2}{l|}{ Horizontal } \\
\hline ISO 6491 & warp & weft & warp & weft & warp & weft \\
\hline WHF-NaOH & X & X & X & X & X & X \\
\hline WHF- FR & X & X & X & X & X & X \\
\hline WHF-NaOH + FR & X & X & X & X & X & X \\
\hline
\end{tabular}

$\mathrm{X}$ - Indicates the expected event had not happened.

In the case of another two treated samples, it was observed that during the flame source exposure, chars was formed on the both of WHF-FR and WHF-NaOH+FR samples and were getting bigger towards the end of exposure. The width and height of the burnt area or char formation on the treated WHF as well as the char formation rate were measured in order to analyse the different effects of flame exposure duration (results are shown in Table 6). The recorded figures were an average of 3 readings for the respective treated WHF sample.

Comparing all the samples in Table 6, the WHF-NaOH sample's burnt area was bigger than the other samples when exposed to flame. This can be seen in Figure 4 (c), (d) and (e). The WHF$\mathrm{NaOH}$ sample burnt width increased by $75 \%$, from $42 \mathrm{~mm}$ to $71 \mathrm{~mm}$ when exposed to flame for 2 minutes while the height increased by $124.5 \%$, from 98 to $220 \mathrm{~mm}$. For the WHF-FR and WHF$\mathrm{NaOH}+\mathrm{FR}$ samples, the width and height of char formation area were about $50 \%$ less than the WHF-NaOH sample for both flame exposure times. Nevertheless, it was observed that the char formation from the WHF-NaOH+FR sample was a little lower than the WHF-FR sample indicating that the combined treatment can give better effect on the fire-retardant properties.

Table 5. Spreading of burnt or char formation for all treated WHF samples

\begin{tabular}{|c|c|c|c|c|c|}
\hline \multirow[t]{3}{*}{ ISO 6491 } & \multicolumn{4}{|c|}{ Burnt/Char formation (mm) } & \multirow{3}{*}{$\begin{array}{c}\text { Char } \\
\text { Formation } \\
\text { Rate for } 120 \text { s } \\
\left(\mathrm{cm} \mathrm{s}^{-1}\right) \\
\end{array}$} \\
\hline & \multicolumn{2}{|c|}{$12 \mathrm{~s}$} & \multicolumn{2}{|c|}{$120 \mathrm{~s}$} & \\
\hline & Width & Height & Width & Height & \\
\hline WHF-NaOH & $\begin{array}{c}43 \\
(2.52)\end{array}$ & $\begin{array}{c}100 \\
(2.08)\end{array}$ & $\begin{array}{c}71 \\
(2.08)\end{array}$ & $\begin{array}{c}220 \\
(2.00)\end{array}$ & 0.183 \\
\hline WHF- FR & $\begin{array}{c}23 \\
(1.00)\end{array}$ & $\begin{array}{c}31 \\
(1.53)\end{array}$ & $\begin{array}{c}38 \\
(1.52)\end{array}$ & $\begin{array}{c}98 \\
(0.91)\end{array}$ & 0.082 \\
\hline $\begin{array}{l}\text { WHF-NaOH } \\
+ \text { FR }\end{array}$ & $\begin{array}{c}20 \\
(0.99)\end{array}$ & $\begin{array}{c}30 \\
(0.95)\end{array}$ & $\begin{array}{c}36 \\
(0.97)\end{array}$ & $\begin{array}{c}87 \\
(1.53)\end{array}$ & 0.073 \\
\hline
\end{tabular}




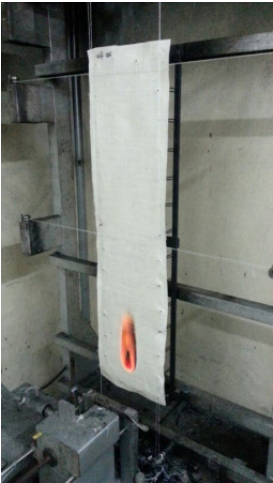

(a)

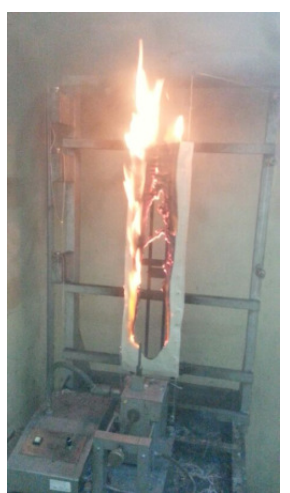

(b)

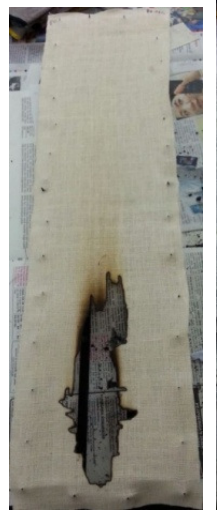

(c)

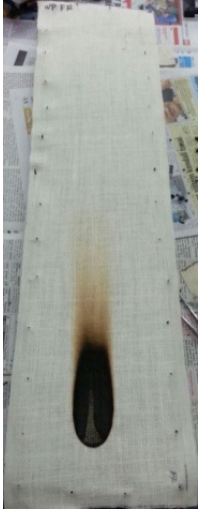

(d)

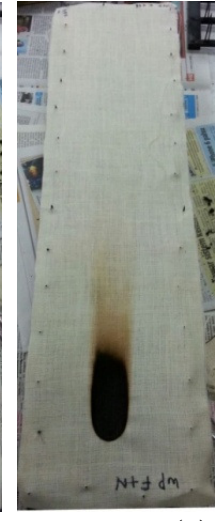

(e)

Figure 3. Flame spreading test photos, a) and b) are WHF-UT specimen under flame spreading test, and samples, c) WHT-NaOH, d) WHF-FR and e) WHF-NaOH+FR after the test

Since all the treated WHF samples were exposed longer to the flame source, the char formations on the fabrics were bigger. Therefore, the char formation rates of all treated WHF samples were possible to be measured. The char formation rate of the WHF-NaOH sample was the highest among all the samples, yet, this rate was far lower than the burning rate of WHF-UT (refer Error! Reference source not found. Table 4). The char formation rates of WHF dropped about 55\% with the incorporation of FR chemical in comparison with WHF- $\mathrm{NaOH}$ and the lowest was possessed by theWHF-NaOH+FR sample. With this char formation rate, in spite of under exaggeration of longer flame time, there is no way that all treated WHF could reach even first mark $(300 \mathrm{~mm})$ during this test. Nevertheless, it was shown that all the treatments on the WHF samples enhanced the flame retardant properties with the best result from the combination of $\mathrm{NaOH}+\mathrm{FR}$, followed by FR and then $\mathrm{NaOH}$.

\subsection{Thermal Properties of Untreated and Treated WHF}

Studies on the thermal decomposition of the treated fabrics were carried out by thermogravimetric (TG) and derivatives themogravimetric (DTG) analyses. Figure 5 (a) and (b) show the TG and DTG curves respectively for all the samples while Table 7 shows the temperature at maximum mass loss rate, mass loss rate and char yield. The TG analysis of untreated WHF (WHF-UT) sample shows that the main pyrolysis started from the onset temperature of degradation at about $220^{\circ} \mathrm{C}$ until $400^{\circ} \mathrm{C}$ and temperature at the maximum mass loss rate was $379^{\circ} \mathrm{C}$ (refer Table 7). At the end of the main pyrolysis, the mass loss due to completed cellulose dehydration accounted for $80 \%$ at $400^{\circ} \mathrm{C}$. The mass loss during this stage was very fast due to the degradation of hemicellulose and cellulose composition in hemp fibres. As the temperature increased, 
hemicellulose was firstly degraded due to the cellular breakdown and then followed by the cellulose which degraded at higher temperature because it was highly crystalline [33,34]. Most of the pyrolysis product of cellulosic were produced in this stage and that included L-Glucose as the major product and combustible gases [19].
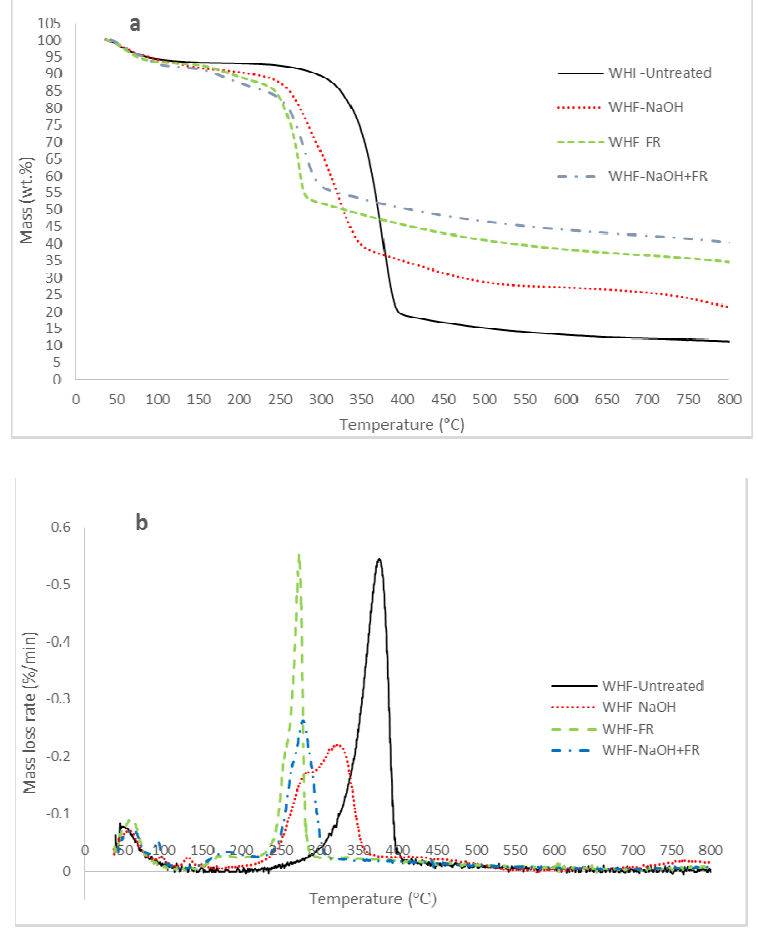

Figure 4. (a) TG and (b) DTG curves of untreated and treated WHF samples

Table 6. Temperature at maximum mass loss rate and char yield at $800^{\circ} \mathrm{C}$ of all WHF samples

\begin{tabular}{|c|c|c|c|c|c|}
\hline Sample & \multirow{2}{*}{$\begin{array}{c}\text { Max. } \\
\text { temperature } \\
\text { of mass loss } \\
\text { rate } \\
\end{array}$} & $\begin{array}{c}\text { Mass loss } \\
\text { rate } \\
\left({ }^{\circ} \mathbf{C}\right)\end{array}$ & $\begin{array}{c}\text { Onset } \\
\text { temperature } \\
\text { of charring } \\
\text { reaction } \\
\left({ }^{\circ} \mathbf{C}\right)\end{array}$ & $\begin{array}{c}\text { Charring } \\
\text { reaction } \\
\text { onset temp. }\end{array}$ & $\mathbf{8 0 0}{ }^{\circ} \mathbf{C}$ \\
\hline WHF-UT & 378.667 & 0.54 & 400 & 19 & 11 \\
\hline WHF-NaOH & 320.528 & 0.22 & 360 & 38 & 21 \\
\hline WHF-FR & 273.219 & 0.55 & 285 & 53 & 35 \\
\hline WHF-NaOH+FR & 278.218 & 0.26 & 310 & 56 & 40 \\
\hline
\end{tabular}

The charring reaction or char pyrolysis of WHF-UT tended to be completed above $400{ }^{\circ} \mathrm{C}$. During this process, dewatering and charring reactions were more dominant than of the L-glucose production. As the dewatering and decarboxylization continued, water and carbon dioxides were released, thus producing double bonds, carboxyl and carbonyl products. The carbon content became higher as the decomposition continued thus forming charred residues. This circumstance is common during the pyrolysis process of cellulosic fibres [18].

As presented in Figure 5, the TG curves for all treated WHF samples indicated that the mass loss started at a lower temperature (shift of about $20-80^{\circ} \mathrm{C}$ ) in comparison with untreated WHF. In the case of WHF-NaOH sample, the mass loss started at $200^{\circ} \mathrm{C}$, reached the maximum mass loss rate at the temperature of $360^{\circ} \mathrm{C}$ and completed dehydration of cellulose accounted $63 \%$ at 
$360^{\circ} \mathrm{C}$. This was lower than the mass loss temperature of the untreated sample (which exceeded the limits) suggesting that cellulose oxidation proceeded under this circumstance and then accompanied by the thermal dehydration of cellulose.

According to Mostashari, et al. [15], $\mathrm{NaOH}$ plays the role of 'dust or wall' which causes heat absorption and dissipation at combustion zone (the zone after char pyrolysis), and consequently if the concentration of $\mathrm{NaOH}$ is high enough (in this case, chemical pickup is high), no flame can propagate. This is because $\mathrm{NaOH}$ is highly stable at elevated temperatures and does not decompose on heating [35]. Hence, for the case of WHF- $\mathrm{NaOH}$ sample, $\mathrm{NaOH}$ which remains intact with hemp fibres absorbs and dissipates the heat thus lowering the temperature and extinguishing out the flame.

Another aspect that should be taken into account is, several flame retardants generate inert gasses such as $\mathrm{CO}_{2}, \mathrm{SO}_{2}, \mathrm{H}_{2} \mathrm{O}, \mathrm{NH}_{3}$, etc. during thermal decomposition. The environment in the area of inflamed substrate could be diluted by the inert gasses and this situation complicates fuel gas such as oxygen access into the flammable volatiles of combustion product [12]. This situation creates flame retardancy and this mechanism is also known as 'gas dilution theory' [36]. With respect to WHF- $\mathrm{NaOH}$, the incorporation of $\mathrm{NaOH}$ in hemp fibre allows it to expel water vapour (acts similarly to inert gas) under burning condition. Therefore, forming of water vapour can absorb a lot of heat in combustion and this treatment could act as a dehydrating flame retardant agent.

The TGA curves for WHF-FR and WHF-NaOH+FR samples indicate weight loss starting at almost the same temperature of about $140^{\circ} \mathrm{C}$, and this is much earlier namely $80^{\circ} \mathrm{C}$ and $60^{\circ} \mathrm{C}$ than WHF-UT and WHF-NaOH respectively. The maximum mass loss temperatures for both samples are given in Table 7 at the temperatures of $273^{\circ} \mathrm{C}$ and $278^{\circ} \mathrm{C}$, then finished at about 285 to $310^{\circ} \mathrm{C}$ for WHF-FR and WHF-NaOH+FR respectively. It shows that, the main pyrolysis stage for WHFFR and WHF-NaOH+FR were commenced and finished earlier than the other two samples. This was due to ammonium polyphosphate which promotes dephosphorylation and acid-catalyzed dehydration of samples catalysed by the nitrogen [37, 38]. This was further supported by the accompanying higher weight loss $(\sim 10 \%)$ compared to untreated WHF $(\sim 6 \%)$ for temperature up to $140^{\circ} \mathrm{C}$ the TG curves. Thus, the incorporation of fire retardant chemical (ammonium polyphosphate) and combination of $\mathrm{NaOH}$ and fire retardant chemical promotes cellulose dehydration at higher degree than the sample treated with $\mathrm{NaOH}$ alone. The char reaction phase for both WHF-FR and WHF-NaOH+FR samples also occurred earlier than other two samples, which started at about 285 and $310^{\circ} \mathrm{C}$ respectively, and their mass loss also became much slower. This is because phosphorus in a sample affects the composition of intermediate chars in the second stage during thermal degradation, slowing down the reaction of the already decomposed residue [38].

\subsection{Limiting Oxygen Index Results}

The LOI measurement test is widely used to evaluate the flammability of materials. It shows the minimum amount of oxygen in oxygen-nitrogen mixture required to support complete combustion of a vertically held sample that burns downward from the top. The higher the LOI value, the more effective the flame-retardant treatment $[38,39]$. There are no indications stated in ASTM: D2683 about the level of fire retardant bases on the LOI value. However, according to Kamath, et al. [9] LOI value more than 28 is generally classified as fire retardant. In accordance with GB50222-1995 standard method, 1) value of $<21$ indicates the material is flammable; 2) value of $\geq 24$ and $<27$ indicates the material is combustible, and; 3) value of $\geq 28$ indicates the material is fire retardant. The results of LOI as shown in Table 8 explain the fire-retardant phenomenon discussed in Section 3.3.

The LOI value for WHF-UT is comparable with the untreated hemp fabric tested by $\mathrm{Xu}$, et al. [38]. Since the value is lower than the 21 , thus the hemp fabric is classified as flammable 
material. That is why untreated hemp was completely burnt and left very minimal residue in the burning test. Treatment with $\mathrm{NaOH}$ on the hemp fabric increased the LOI value to 24 and this is clustered under combustible material. When the WHF-NaOH sample was subjected to burning test, the ignition of fire produced yellow flame. Even though the flame could be self-extinguished, smoulder was produced and kept burning char residue (refer Section 3.3). This fabric can still be burnt by the exaggeration of other fire sources.

The LOI value for the WHF-FR sample was more than 28, thus this sample is clustered as fire retardant. During the burning test, there was no ignition or smoulder produced but the rapid formation of char was noticed. In $\mathrm{Xu}$, et al. [38], hemp fabric treated with phosphorus only compound possessed LOI value of 27 and this figure is just enough to be fire retardant. However, with the addition of phosphorus percentage and other compound such as nitrogen, halogen and boron in the formulation, they managed to increase the LOI value of treated hemp fabric up to 41. Therefore, it can be assumed that either the ammonium polyphosphate content is high or the other chemical compound exist in the fire retardant chemical which attributed to the highest LOI value to the WHF in this work. In the case of WHF- $\mathrm{NaOH}+\mathrm{FR}$, there is high probability that the $\mathrm{NaOH}$ content leads to the decrement of LOI value. However, under the burning test, the burning characteristics were physically similar with the WHF-FR sample.

Table 8. LOI results of all WHF samples

\begin{tabular}{|c|c|}
\hline Samples & LOI \\
\hline WHF-UT & 18.6 \\
\hline WHF-NaOH & 24.2 \\
\hline WHF-FR & 51.0 \\
\hline WHF-NaOH+FR & 49.4 \\
\hline
\end{tabular}

\subsection{Effect of Chemical Treatment on the Mechanical Properties}

The study on the behaviour of WHF can be clustered into three phases. The first phase is the initial region, demonstrated by a curve with a low slope, the second phase is the linear region of the curve, which rises steeply until its summit is reached and the third phase is the curve after it reaches the peak $[16,26]$.
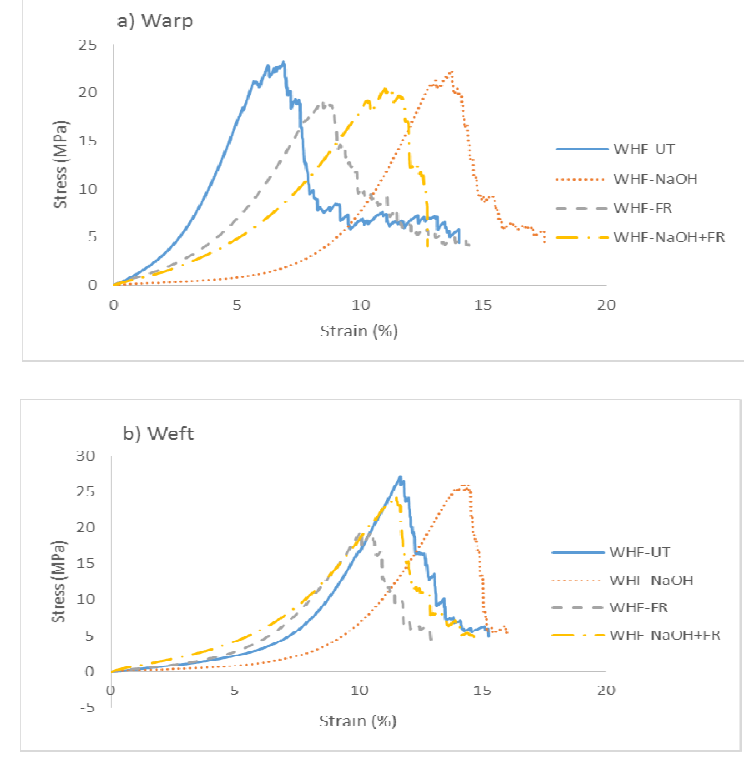

Figure 6. Typical tensile stress-strain response for, (a) warp and (b) weft of all WHF samples 
Table 9. Summary of tensile properties for all WHF samples

\begin{tabular}{|c|c|c|c|c|c|}
\hline Sample & & $\begin{array}{l}\text { Peak Load } \\
(\mathbb{N})\end{array}$ & $\begin{array}{c}\text { Tensile } \\
\text { Strength } \\
\text { (MPa) }\end{array}$ & $\begin{array}{c}\text { Tensile Strain } \\
\text { at Peak }(\%)\end{array}$ & $\begin{array}{l}\text { Tensile } \\
\text { Modulus } \\
\text { (GPa) }\end{array}$ \\
\hline \multirow[t]{2}{*}{ WHF-UT } & Warp & $\begin{array}{l}444.440 \\
(13.65)\end{array}$ & $23.515(0.72)$ & $6.459(0.389)$ & $\begin{array}{c}0.590 \\
(0.0098)\end{array}$ \\
\hline & Weft & $\begin{array}{l}510.88 \\
(8.396)\end{array}$ & $\begin{array}{l}27.031 \\
(0.448)\end{array}$ & $11.187(0.37)$ & $0.621(0.026)$ \\
\hline \multirow[t]{2}{*}{ WHF-NaOH } & Warp & $\begin{array}{c}427.420 \\
(30.74)\end{array}$ & $22.615(1.63)$ & $\begin{array}{l}13.992 \\
(0.508)\end{array}$ & $\begin{array}{c}0.442 \\
(0.0103)\end{array}$ \\
\hline & Weft & $\begin{array}{l}493.18 \\
(24.73)\end{array}$ & $\begin{array}{l}26.094 \\
(1.308)\end{array}$ & $\begin{array}{l}14.893 \\
(0.787)\end{array}$ & $0.445(0.008)$ \\
\hline \multirow[t]{2}{*}{ WHF-FR } & Warp & $\begin{array}{c}365.740 \\
(6.395)\end{array}$ & $\begin{array}{l}19.351 \\
(0.338)\end{array}$ & $8.323(0.417)$ & $0.398(0.026)$ \\
\hline & Weft & $\begin{array}{l}394.26 \\
(33.61)\end{array}$ & $\begin{array}{l}20.860 \\
(1.778)\end{array}$ & $\begin{array}{l}11.048 \\
(0.647)\end{array}$ & $\begin{array}{l}0.41263 \\
(0.0100)\end{array}$ \\
\hline \multirow[t]{2}{*}{$\begin{array}{c}\text { WHF- } \\
\mathrm{NaOH}+\mathrm{FR}\end{array}$} & Warp & $\begin{array}{l}380.080 \\
(24.66)\end{array}$ & $\begin{array}{l}20.110 \\
(1.302)\end{array}$ & $\begin{array}{c}11.096 \\
(0.0044)\end{array}$ & $0.338(0.028)$ \\
\hline & Weft & $\begin{array}{c}462.64 \\
(10.779)\end{array}$ & $\begin{array}{l}24.478 \\
(0.571)\end{array}$ & $\begin{array}{l}11.650 \\
(0.362)\end{array}$ & $\begin{array}{c}0.360 \\
(0.0391)\end{array}$ \\
\hline
\end{tabular}

Figures in bracket indicate standard deviation

Figure 6 shows the typical tensile stress-strain response for all the WHF samples. Each sample were cut and tested in the warp and weft direction. Table 9 summarizes the average tensile properties for each WHF samples. The tensile properties reported are the average and standard deviation from all the specimens.

For the warp direction (Figure 6(a)), every WHF sample possessed different curves due to the variation in the strain percentage. The strain percentages were varied due to the chemical treatments applied on each WHF sample which affected their yarn crimp (originally 6\% as shown in Table 1) and disclosed as fabric shrinkage percentage (as shown in Table 2). When the treatments were applied on the WHF samples, the fibres were swollen and as a consequence, the whole fabric system experienced shrinkages and this was discussed in detail in Section 3.2. Based on Table 2, in the warp direction, the WHF-NaOH sample exhibited the highest fabric shrinkage, followed by WHF-NaOH+FR and the lowest was possessed by WHF-FR. For the sample with higher fabric shrinkage, it took more time for the yarn to be straightened thus affected the overall strain percentage (Table 9) of each sample.

In terms of tensile strength, the highest was possessed by the WHF-UT sample and then decreased by the chemical treatment applied on them. In the case of WHF- $\mathrm{NaOH}, \mathrm{NaOH}$ removed hemicellulose and lignin partially from the fibres resulting in easy deformations of cellulose microfibrils during tensile loading. The presence of hemicellulose and lignin held the mircrofibrils in position and resisted slippage when subjected to tensile loading. Thus the losses of some hemicellulose and lignin in fibre weakened the bonding of microfibrils thus resulted in lower tensile properties as compared to untreated fibres [40, 41]. For the WHF-FR sample, there is high possibility that some amount of cellulose in the hemp fibre was hydrolysed during the fire retardant treatment which caused minor degradation then resulting to the decrease in it strength $[11,29,42]$. This is because the ammonium polyphosphate compound in fire retardant is an inorganic salt of polyphosphoric acid and it might be dissolved or hydrolysed in acid solution [43, 44]. In the case of WHF-NaOH+FR, since the fabric was firstly treated with $\mathrm{NaOH}$, the strength was reduced due to the reason discussed above. It was then further decreased a bit due to the FR treatment but since the fibres was already deposited by $\mathrm{NaOH}$, the FR (ammonium polyphosphate) reacted majorly with $\mathrm{NaOH}$ to produce salt. Therefore, tensile strength of WHF$\mathrm{NaOH}+\mathrm{FR}$ was a bit higher than WHF-FR.

Treatment with $\mathrm{NaOH}$ (WHF-NaOH) decreases the tensile modulus due to the elimination of some hemicellulose and lignin because other than tensile strength, the stiffness of the hemp fibre 
is depended on these two compounds [46]. It was worse when the WHF was treated with FR chemical (WHF-FR) due to the hydrolisation of some cellulose compound. In the case of WHF$\mathrm{NaOH}+\mathrm{FR}$, higher tensile strength was achieved but possessed lower tensile modulus than WHFFR. Since the WHF was firstly treated with $\mathrm{NaOH}$ and consecutively with the FR chemical, most probably FR chemical was responsible for the further elimination of hemicellulose and lignin thus decreased the tensile modulus of WHF-NaOH+FR sample.

In terms of the weft direction, all mechanical properties shown in Table 9 followed the similar trend with warp direction except for the tensile strain. The original yarn crimp for weft yarn was longer (9.3\%) than warp (6\%) (refer Table 2). It is normal for weft yarn to have a higher yarn crimp than warp yarn due to the tension arrangement during the process of weaving [16, 26, 43]. After the treatments, all treated samples in weft direction WHF shrunk but the shrinkage percentages were lower than warp direction. This is due to the higher density of fabric in warp direction which prevents the weft yarn to shrink further. As a consequence, the built-up pressure in the weft is getting higher and this is the reason why the tensile strength and modulus of weft yarn were higher than warp yarn tension. Thus, higher load is needed to overcome the weft yarns' built-up pressure apart from its higher yarn size (refer Table 1).

\section{Conclusions}

Impregnation of $\mathrm{NaOH}$, FR chemical and combination of both demonstrated an improvement in flame retardant properties of woven hemp fabric. The detailed analyses on the treated woven hemp fabrics showed several findings which are important for this material to be used not only in textile and apparel but also in technical and engineering fields. The treatments really affect the physical properties of the woven hemp fabric. The densities increased from 1.47 to $1.53 \mathrm{~g} / \mathrm{cm}^{3}$ depending on the treatments. The fabric also shrunk within the range of 1.67 to $5 \%$ and 0.67 to $3 \%$ for warp and weft, respectively. The changes are attributed to the changing of physical properties of woven hemp fibre. The fibre cross-section changed from elliptical to more rounder and clean surface by $\mathrm{NaOH}$, deposition of particle by FR on the fibre surfaces and salt deposition by the combination of $\mathrm{NaOH}$ and FR treatments.

In this work, a method of measuring burning rate on the fire-retardant sample was established. Using this method, it was proven that the treated WHF showed good results against the fire. Nevertheless, WHF treated with FR and combination between $\mathrm{NaOH}$ and FR were found to be better than the $\mathrm{NaOH}$ treatment. In terms of thermogravimetric analyses, impregnation of treatments improved the onset of WHF main pyrolysis from $220{ }^{\circ} \mathrm{C}$ to much earlier which is 140 ${ }^{\circ} \mathrm{C}$. The earlier pyrolysis indicated faster cellulose dehydration and promoted char formation. The char yield at $800{ }^{\circ} \mathrm{C}$ showed that the treatment with the combination of $\mathrm{NaOH}$ and FR chemical could produce good char residue which was $40 \%$. In terms of LOI, the sample treated with FR chemical showed the highest value (51) among all other samples suggesting that this is fire retardant material and followed by sample treated with $\mathrm{NaOH}$ and FR (49.4). The sample treated with only $\mathrm{NaOH}$ is clustered under combustible because its LOI was lower than 27 . In terms of tensile properties, the treatment reduces the strength of WHF for all tensile parameters ranging from 18 to $32 \%$ and 23 to $39 \%$ for warp and weft respectively. All the treatments significantly improved the fire retardant properties of woven hemp fabric however the mechanical properties were reduced.

\section{ACKNOWLEDGEMENTS}

The authors would like to thank the Ministry of Higher Education, Malaysia and Universiti Teknologi MARA, Malaysia for providing the scholarship to the first author on doing this work. 


\section{REFERENCES}

[1] T. M. Kotresh, R. Indushekar, M. S. Subbulakshmi, S. N. Vijayalakshmi, A. S. K. Prasad, and A. K. Agrawal, "Evaluation of Commercial Flame Retardant Polyester Curtain Fabrics in the Cone Calorimeter," Journal of Industrial Textiles, vol. 36, no. 1, pp. 47-58, July 1, 20062006.

[2] P. Bajaj, "Heat and Flame Protection," in Handbook of Technical Textile, A. R. Horrocks and S. C. Anand, Eds. North and South America: Woodhead Publishing Limited \& The Textile Institute, 2000, pp. 223-263.

[3] S. J. Kadolph, Textiles, 10th ed. ed. Upper Saddle River, N.J.: Pearson Prentice Hall, 2007.

[4] D. B. Dittenber and H. V. S. GangaRao, "Critical review of recent publications on use of natural composites in infrastructure," Composites Part A: Applied Science and Manufacturing, vol. 43, no. 8, pp. 1419-1429, 8// 2012.

[5] O. Faruk, A. K. Bledzki, H.-P. Fink, and M. Sain, "Biocomposites reinforced with natural fibers: 2000-2010," Progress in Polymer Science, vol. 37, no. 11, pp. 1552-1596, 11// 2012.

[6] A. Maslinda, M. A. Majid, M. Ridzuan, M. Afendi, and A. Gibson, "Effect of water absorption on the mechanical properties of hybrid interwoven cellulosic-cellulosic fibre reinforced epoxy composites," Composite Structures, vol. 167, pp. 227-237, 2017.

[7] M. I. Misnon, M. M. Islam, J. A. Epaarachchi, and K.-t. Lau, "Selection of hemp fabric as reinforcement in composite materials," in Proceedings of the 3rd International Conference on Mechanical, Industrial and Energy Engineering (ICMIEE 2014), 2014, pp. 1-5: Khulna University of Engineering \& Technology.

[8] H. Hargitai, I. Rácz, and R. D. Anandjiwala, "Development of HEMP Fiber Reinforced Polypropylene Composites," Journal of Thermoplastic Composite Materials, vol. 21, no. 2, pp. 165 174, March 1, 20082008.

[9] M. G. Kamath, G. S. Bhat, D. V. Parikh, and B. D. Condon, "Processing and Characterization of Flame Retardant Cotton Blend Nonwovens for Soft Furnishings to Meet Federal Flammability Standards," Journal of Industrial Textiles, vol. 38, no. 3, pp. 251-262, January 1, 20092009.

[10] W. Wu and C. Q. Yang, "Comparison of different reactive organophosphorus flame retardant agents for cotton. Part II: Fabric flame resistant performance and physical properties," Polymer Degradation and Stability, vol. 92, no. 3, pp. 363-369, 3// 2007.

[11] A. R. Horrocks, "Flame retardant challenges for textiles and fibres: New chemistry versus innovatory solutions," Polymer Degradation and Stability, vol. 96, no. 3, pp. 377-392, 3// 2011.

[12] R. Uppal, G. Bhat, K. Akato, D. V. Parikh, S. Nam, and B. Condon, "Flame retardant antibacterial cotton high-loft nonwoven fabrics," Journal of Industrial Textiles, vol. 41, no. 4, pp. 281-291, April 1, 20122012.

[13] F. Shafizadeh, P. S. Chin, and W. F. DeGroot, "Mechanistic Evaluation of Flame Retardants," Fire Retardant Chemistry, vol. 2, pp. 195-203, 1975.

[14] Y. Chen, A. Frendi, S. S. Tewari, and M. Sibulkin, "Effects of fire retardant addition on the combustion properties of a charring fuel," Fire Safety Sciences, vol. 3, pp. 527-536, 1991.

[15] S. M. Mostashari, Y. K. Nia, and F. Fayyaz, "Thermogravimetry of deposited caustic soda used as a flame-retardant for cotton fabric," (in English), Journal of Thermal Analysis and Calorimetry, vol. 91, no. 1, pp. 237-241, 2008/01/01 2008.

[16] M. I. Misnon, M. M. Islam, J. A. Epaarachchi, and K. T. Lau, "Analyses of woven hemp fabric characteristics for composite reinforcement," Materials \& Design, vol. 66, Part A, no. 0, pp. 82-92, 2/5/ 2015.

[17] X. Chen and G. A. V. Leaf, "Engineering Design of Woven Fabrics for Specific Properties," Textile Research Journal, vol. 70, no. 5, pp. 437-442, May 1, 20002000.

[18] P. Zhu, S. Sui, B. Wang, K. Sun, and G. Sun, "A study of pyrolysis and pyrolysis products of flameretardant cotton fabrics by DSC, TGA, and PY-GC-MS," Journal of Analytical and Applied Pyrolysis, vol. 71, no. 2, pp. 645-655, 6// 2004. 
Advances in Materials Science and Engineering: An International Journal (MSEJ), Vol. 5, No. 1, March 2018

[19] G. Brancatelli, C. Colleoni, M. R. Massafra, and G. Rosace, "Effect of hybrid phosphorus-doped silica thin films produced by sol-gel method on the thermal behavior of cotton fabrics," Polymer Degradation and Stability, vol. 96, no. 4, pp. 483-490, 4// 2011.

[20] M. Försth, H. Modin, and B. Sundström, "A comparative study of test methods for assessment of fire safety performance of bus interior materials," Fire and Materials, vol. 37, no. 5, pp. 350-357, 2013.

[21] R. M. Rossi, G. Bruggmann, and R. Stämpfli, "Comparison of flame spread of textiles and burn injury prediction with a manikin," Fire and Materials, vol. 29, no. 6, pp. 395-406, 2005.

[22] S. F. Grgac, B. Lozo, and D. Banić, "Flame retardancy of paper obtained with environmentally friendly agents," Fibres \& Textiles in Eastern Europe, vol. 17, no. 3, p. 74, 2009.

[23] A. Cireli et al., "Development of flame retardancy properties of new halogen-free phosphorous doped $\mathrm{SiO} 2$ thin films on fabrics," Journal of Applied Polymer Science, vol. 105, no. 6, pp. 3748-3756, 2007.

[24] M. F. Yahya, J. Salleh, and W. Y. W. Ahmad, "Uniaxial failure resistance of square-isotropic 3D woven fabric modelled with finite element analysis," in Business, Engineering and Industrial Applications (ISBEIA), 2011 IEEE Symposium on, 2011, pp. 16-21.

[25] X. Huang and A. Netravali, "Characterization of flax fiber reinforced soy protein resin based green composites modified with nano-clay particles," Composites Science and Technology, vol. 67, no. 10, pp. 2005-2014, 8// 2007.

[26] J. Hu, Structure and mechanics of woven fabrics. North America: Published by Woodhead Publishing Limited in association with The Textile Institute, Woodhead Publishing Ltd, 2004.

[27] P. Zugenmaier, "Cellulose," Crystalline Cellulose and Derivatives: Characterization and Structures, pp. 101-174, 2008.

[28] B. Madsen, P. Hoffmeyer, A. B. Thomsen, and H. Lilholt, "Hemp yarn reinforced composites - I. Yarn characteristics," Composites Part A: Applied Science and Manufacturing, vol. 38, no. 10, pp. 2194-2203, 10// 2007.

[29] Y. L. Lam, C. W. Kan, and C. W. M. Yuen, "Flame-retardant finishing in cotton fabrics using zinc oxide co-catalyst," Journal of Applied Polymer Science, vol. 121, no. 1, pp. 612-621, 2011.

[30] J. Alongi, F. Carosio, and G. Malucelli, "Influence of ammonium polyphosphate-/poly(acrylic acid)based layer by layer architectures on the char formation in cotton, polyester and their blends," Polymer Degradation and Stability, vol. 97, no. 9, pp. 1644-1653, 9// 2012.

[31] C. E. Anderson, D. E. Ketchum, and W. P. Mountain, "Thermal conductivity of intumescent chars," Journal of Fire Sciences, vol. 6, no. 6, pp. 390-410, 1988.

[32] G. Camino, L. Costa, E. Casorati, G. Bertelli, and R. Locatelli, "The oxygen index method in fire retardance studies of polymeric materials," Journal of Applied Polymer Science, vol. 35, no. 7, pp. 1863-1876, 1988.

[33] M. R. Ishak, S. M. Sapuan, Z. Leman, M. Z. A. Rahman, and U. M. K. Anwar, "Characterization of sugar palm (Arenga pinnata) fibres," (in English), Journal of Thermal Analysis and Calorimetry, vol. 109, no. 2, pp. 981-989, 2012/08/01 2012.

[34] H. Yang, R. Yan, H. Chen, D. H. Lee, and C. Zheng, "Characteristics of hemicellulose, cellulose and lignin pyrolysis," Fuel, vol. 86, no. 12-13, pp. 1781-1788, 8// 2007.

[35] A. K. De, A text book of inorganic chemistry. New Age International, 2007.

[36] J. H. Troitzsch, "Overview of flame retardants," Chemistry today, vol. 16, 1998.

[37] B. Kandola, A. Horrocks, D. Price, and G. Coleman, "Flame-retardant treatments of cellulose and their influence on the mechanism of cellulose pyrolysis," Journal of Macromolecular Science, Part C: Polymer Reviews, vol. 36, no. 4, pp. 721-794, 1996.

[38] J. Z. Xu et al., "Study on the Thermal Degradation of Cellulosic Fibers Treated with Flame Retardants," Journal of Fire Sciences, vol. 20, no. 3, pp. 227-235, May 1, 20022002. 
[39] F. Shukor, A. Hassan, M. Saiful Islam, M. Mokhtar, and M. Hasan, "Effect of ammonium polyphosphate on flame retardancy, thermal stability and mechanical properties of alkali treated kenaf fiber filled PLA biocomposites," Materials \& Design, vol. 54, pp. 425-429, 2// 2014.

[40] M. M. Kabir, H. Wang, K. T. Lau, and F. Cardona, "Effects of chemical treatments on hemp fibre structure," Applied Surface Science, vol. 276, no. 0, pp. 13-23, 7/1/ 2013.

[41] B. Madsen, P. Hoffmeyer, and H. Lilholt, "Hemp yarn reinforced composites - II. Tensile properties," Composites Part A: Applied Science and Manufacturing, vol. 38, no. 10, pp. 2204-2215, 10// 2007.

[42] C. Q. Yang, Weishu Wei, and G. C. Lickfield, "Mechanical Strength of Durable Press Finished Cotton Fabric: Part III: Change in Cellulose Molecular Weight," Textile Research Journal, vol. 70, no. 10, pp. 910-915, October 1, 20002000.

[43] S. J. Kadolph and A. L. Langford, Textiles, 9th ed. New Jersey:: Prentice Hall, 2001.

[44] J. Zhang et al., "Dissolution of microcrystalline cellulose in phosphoric acid-Molecular changes and kinetics," Molecules, vol. 14, no. 12, pp. 5027-5041, 2009.

[45] S. J. Christian and S. L. Billington, "Mechanical response of PHB- and cellulose acetate natural fiberreinforced composites for construction applications," Composites Part B: Engineering, vol. 42, no. 7, pp. 1920-1928, 10// 2011.

[46] Z. N. Azwa, B. F. Yousif, A. C. Manalo, and W. Karunasena, "A review on the degradability of polymeric composites based on natural fibres," Materials \& Design, vol. 47, pp. 424-442, 5// 2013.

\section{AUTHOR}

Dr Md Mainul Islam is currently a Senior Lecturer in Mechanical Engineering at University of Southern Queensland (USQ), Australia. He completed his PhD in Mechanical Engineering with Polymeric Composite Materials major at the University of Newcastle, Australia. He is a graduate and also former Assistant Professor in Mechanical Engineering of Khulna University of Engineering \& Technology (KUET), previously known as BIT Khulna, Bangladesh. He got his MEng degree in Structural Engineering with Fracture Mechanics major from Kyushu University, Japan. His research interests are in the areas of fibre and

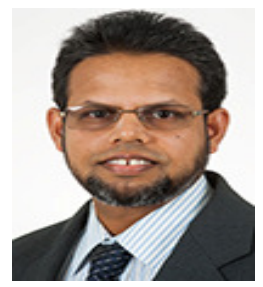
particulate composite materials especially for infrastructure and biomedical applications. He also belongs to the Centre for Future Materials at USQ. He has over 100 research publications based on his area of research. He serves as Editorial Board member for several renowned journals and as a Technical Committee member for several international conferences. 